\title{
TRICOMAS CONFEREM RESISTÊNCIA CONTRA HERBIVORIA DE Cerotoma arcuata EM CULTIVARES DE SOJA
}

\author{
Diego de Macedo Rodrigues ${ }^{1}$, Cíntia Ribeiro Souza², Raimundo Wagner de Souza Aguiar ${ }^{3}$, \\ Aurélio Vaz de Melo ${ }^{4}$, Jucielle Cardoso da Silva ${ }^{5}$, Márcio Akio Ootani ${ }^{6}$, Wilton Pires da Cruz ${ }^{7}$. \\ ${ }^{1}$ Professor Assistente I, Universidade Federal do Pará (UFPA), Marabá - PA, diegomacedoagronomo@ hotmail.com \\ ${ }^{2}$ Professora Permanente, Instituto Federal do Pará, IFPA, C. do Araguaia-PA, cintiarvm@uft.edu.br \\ ${ }^{3}$ Professor Adjunto II, Universidade Federal do Tocantis, UFT, Gurupi - TO, rswaguiar@uft.edu.br \\ ${ }^{4}$ Professor Adjunto I, Universidade Federal do Tocantis, UFT, Gurupi - TO, vazdemelo@uft.edu.br \\ ${ }^{5}$ Bolsista Mestre, Embrapa Agroenergia , Brasília - DF, juciellec@yahoo.com.br \\ ${ }^{6}$ Doutorando em Agronomia, Universidade Federal do Ceará, UFC, Fortaleza - CE, ootani667@uft.edu.br \\ ${ }^{7}$ Doutorando em Entomologia Agrícola, Universidade Estadual Paulista, UNESP, Jaboticabal - SP, wilton@uft.edu.br
}

RESUMO: O uso de cultivares de soja resistente a insetos-praga é uma alternativa de controle que diminui os custos de produção e não causa desequilíbrio no agroecossistema. Assim, objetivou-se com este trabalho avaliar se diferentes densidades de plantio influenciam a suscetibilidade de cultivares de soja a Cerotoma arcuata Oliver (Coleoptera: Chrysomelidae) no estado do Tocantins. Para tanto, foram conduzidos ensaios de preferência com chance de escolha em laboratório utilizando os cultivares de soja P98Y70, M8766RR e M9144RR. A preferência dos insetos variou em função da cultivar. Os tricomas desempenham papel importante na proteção das plantas ao ataque da C. arcuata, de forma que o cultivar M8766RR apresenta resistência do tipo nãopreferência para alimentação deste desfolhador.

PALAVRAS-CHAVE: defesas morfológicas, manejo de resistência, relação inseto-planta.

\section{TRICHOMES CONFER RESISTANCE AGAINST HERBIVORY Cerotoma arcuata IN SOYBEAN CULTIVARS}

\begin{abstract}
The use of soybean cultivars resistant to insect pest control is an alternative that reduces production costs and does not cause an imbalance in the agroecosystem. Thus, the aim of this work was to evaluate whether different planting densities influence the susceptibility of soybean to Cerotoma arcuata Oliver (Coleoptera:Chrysomelidae) in the state of Tocantins. To this end, preference tests with multiple choices were conducted on laboratory using soybean cultivars P98Y70, M8766RR and M9144RR. The preference of insects varied depending on the cultivar. Trichomes play an important role in the protection of plants to attack by $C$. arcuata, so that the cultivar M8766RR is resistant of the non-feeding preference of this defoliator
\end{abstract}

KEY-WORDS: insect-plant relationship, morphological defenses, resistance management.

\section{INTRODUÇÃO}

O crisomelídeo, Cerotoma arcuata Olivier

(Coleoptera: Chrysomelidae), é um dos insetos-praga de maior importância na cultura de soja no Brasil, uma vez que provoca desfolhamento severo nas plantas, reduzindo a capacidade fotossintética e, consequentemente, de produção de grãos (DIDONET et al., 1998). Entretanto, a grande dificuldade no controle de C. arcuata na cultura de soja é a ausência de 
conhecimento dos aspectos bioecológicos e de formas alternativas de controle desta praga. Mesmo assim, poucos estudos estão sendo direcionados ao manejo integrado de pragas na cultura de soja.

Neste contexto, o manejo desta praga é predominantemente baseado no controle químico. A utilização do controle químico, baseada apenas na presença do inseto alimentando-se das folhas da cultura, é ecologicamente incorreta podendo ocasionar desequilíbrios populacionais e aquisição de resistência desses insetos aos produtos químicos. Adicionalmente pode ocasionar a contaminação do meio ambiente (solo, água, atmosfera e seres vivos) e danos acidentais pelo uso irracional dos produtos (HAJEK, 2004).

Por outro lado, o uso de cultivares resistente é uma das alternativas que minimiza o ataque do inseto à planta, reduzindo o número de aplicações de inseticidas no controle $C$. arcuata na cultura da soja. Lima e Lara (2004) recomendam o uso de cultivares resistentes como tática ideal no controle de insetos-praga na cultura de soja, por apresentar custos compatíveis, não causar desequilíbrios ecológicos, não interferir com outras práticas agrícolas e permitir boa eficiência de controle do inseto em níveis baixos de população. Dentre os três tipos de resistência, a não-preferência para alimentação é um dos mais comuns e, segundo Kogan (1980) pode-se realizar a seleção de cultivares mais resistentes por meio de simples medidas do consumo realizado pelo inseto.

Diante do exposto, o objetivo deste trabalho é avaliar as relações da densidade de tricomas foliares em diferentes cultivares de soja com o consumo de C. arcuata.

\section{MATERIAL E MÉTODOS}

Os experimentos foram conduzidos na Universidade Federal do Tocantins - Campus de Gurupi-TO. Para avaliar o consumo e a preferência de $C$. arcuata em três cultivares (P98Y70, M8766RR e M9144RR) foram utilizados discos foliares em ensaios de laboratório. $\mathrm{O}$ delineamento utilizado foi $\mathrm{o}$ inteiramente casualizado, com dez repetições e três tratamentos. Dez folhas não danificadas foram retiradas da região mediana das plantas aleatoriamente de parcelas cultivadas em campo. Da porção central destas folhas foram retirados os discos $(\varnothing=3 \mathrm{~cm})$, estes tiveram aferido seu peso em balança de precisão, em seguida foram posicionados de forma equidistantes em uma placa de Petri. Cada placa recebeu um disco de cada genótipo de soja, o que constituiu uma repetição. Posteriormente, quatro indivíduos adultos de $C$. arcuata foram liberados no centro da placa, que em seguida foi tampada. As placas foram alocadas em sala climatizada com temperatura de $27 \pm 2{ }^{\circ} \mathrm{C}$, U. R. $75 \pm 10 \%$ e fotoperíodo de 12 horas.

Durante 12 horas, em intervalos de três horas, o peso dos discos foi mensurado, 
totalizando cinco avaliações, considerando como primeira avaliação a pesagem inicial dos discos.

A contagem do número de tricomas foi realizada através de um microscópio estereoscópico (aumento 40x) com câmara clara. As contagens foram realizadas em discos de $0,5 \mathrm{~cm}$ de diâmetro na face abaxial e adaxial, utilizando-se a média das duas faces. Foram utilizados dois discos por estrato foliar (apical, mediano e basal) retirados de locais equidistantes da nervura central, totalizando seis discos por repetição, totalizando três repetições.

Os valores de densidade de tricomas e massa foliar consumida foram correlacionados por meio de regressão polinomial, também foram submetidos à análise de variância e as médias comparadas pelo teste de Tukey a $5 \%$ de probabilidade. As análises de variância e testes de médias foram realizados utilizando-se o programa Statistica 7.0 - StatSoft Inc. 2004 e a regressão foram confeccionados utilizando- se o programa Sigmaplot 11.0 - SystatSoft Inc. 2008.

\section{RESULTADOS E DISCUSSÃO}

A maior densidade de tricomas $(\mathrm{p} \leq 0,05)$ foi observada na cultivar M8766RR (52,8 tricomas/disco), contra 40,8 e 46,7 tricomas/disco nos cultivares P98Y70 e M9144RR, respectivamente. $C$. arcuata consumiu em maior quantidade os discos foliares de M944RR ( $\mathrm{p} \leq 0,05)$ (Figura 1).

Os insetos consumiram em média 41,55 mg dos discos foliares desta cultivar ao fim das 12 horas de avaliação. A cultivar M8766RR apresentou o menor valor médio de massa foliar consumida, 10,40 $\mathrm{mg}$, caracterizando a não-preferência para alimentação.

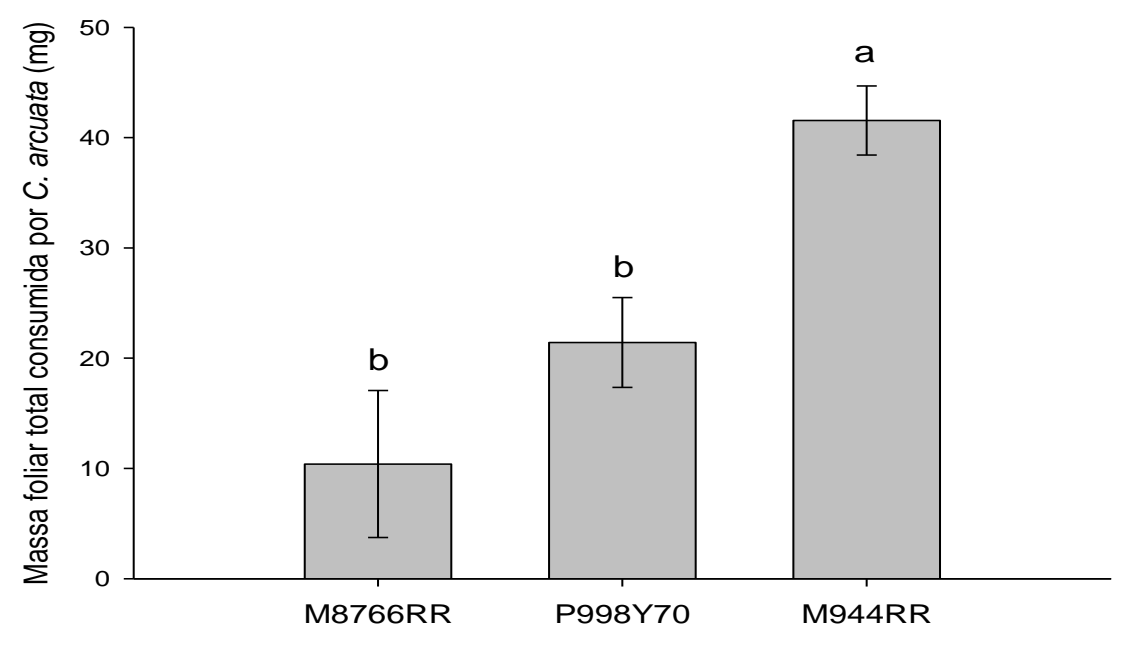

Figura 1. Massa foliar total consumida por Cerotoma arcuata das cultivares de soja M8766RR, P998Y70 e M944RR no período de 12 horas. 
A cultivar M8766RR apresentou-se menos suscetível ao ataque de $C$. arcuata em função da menor média de área danificada nos discos foliares. A maior média de tricomas observada nesta cultivar, pode indicar que, neste caso, estas estruturas podem ter influenciado diretamente na redução do ataque deste crisomelídeo nas folhas. Tricomas são adaptações vantajosas às plantas de ambientes secos, com luz ou vento intenso, podendo reduzir a perda de água por transpiração (LEVIN, 1973; MEDEIROS; MORRETES, 1995; KARABOURNIOTIS et al., 1999; ALMEIDA, 2005). Estas estruturas também podem afetar a oviposição, por liberar substâncias que podem repelir os insetos pelo odor ou palatabilidade. Isso por apresentar compostos de terpenos, fenóis ou alcalóides ou apresentar formas que dificultam a locomoção sobre a superfície foliar, funcionando como obstáculo, podendo se apresentar em diferentes densidades, formas e tamanhos (ALMEIDA, 2005).

$\mathrm{Na}$ evolução do consumo da massa foliar por C. arcuata em discos foliares das diferentes cultivares nos intervalos de 3, 6, 9 e 12 horas após a liberação dos insetos, a cultivar M944RR apresentou valores superiores aos demais em todos os intervalos $(\mathrm{p} \leq 0,05)$ (Figura 2).

As cultivares P9988Y70 e M8766RR apresentaram valores $(p \leq 0,05)$ iguais nas avaliações 6, 9 e 12 horas após a liberação dos insetos, diferindo-se apenas na avaliação de três horas. Desta forma, observou-se uma preferência alimentar da $C$. arcuata pela cultivar M9144RR.

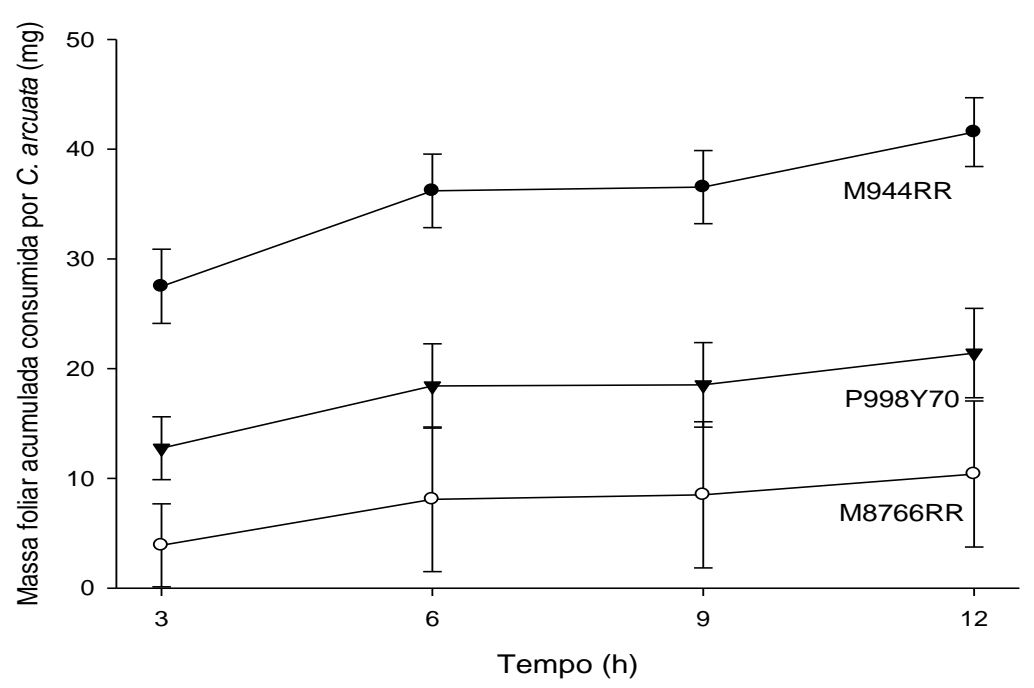

Figura 2. Massa foliar consumida por Cerotoma arcuata das cultivares de soja M8766RR, P998Y70 e M944RR, avaliadas 3, 6, 9 e 12 horas após a liberação dos insetos. 
Com relação à presença de tricomas, a cultivar M9144RR apresentou apenas valores medianos em relação às demais. Acredita-se que, neste caso, a proteção das folhas esteja diretamente relacionada com a densidade de tricomas. Contudo, estudos mais específicos devem ser realizados, inclusive qualificandose os tipos e tamanhos de tricomas envolvidos na repelência de $C$. arcuata nos diferentes cultivares de soja.

Neste sentido Levin (1973), afirma que algumas folhas apresentam tricomas com formas variadas: unicelulares ou multicelulares, glandulares ou nãoglandulares, retos, em espiral ou em gancho, tortuosos, simples, peltados ou estrelados, variando em forma e densidade nos diferentes órgãos da planta. Alguns desenvolvem espessas paredes secundárias, algumas vezes impregnadas com sílica e carbonato de cálcio. Os glandulares acumulam ácidos, terpenos, gomas e ou taninos. O contato dos insetos com essas substâncias promove repelência, imobilidade dos membros ou, ainda, toxidez, podendo matar o inseto. Este fato pode ser um indicativo de que poucos tricomas especializados em repelência química podem surtir mais efeito do que muitos tricomas de repelência mecânica, por isso a importância da qualificação dos mesmos.

A densidade de tricomas na folhas, independentemente da cultivar, em função da porcentagem de dano causado por C. arcuata (Figura 3) ajustou-se ao modelo de regressão quadrática com $\mathrm{R}^{2}$ igual a $0,6132(\mathrm{p} \leq 0,05)$. De acordo com a curva de tendência a densidade de tricomas foi inversamente proporcional ao aumento da massa foliar consumida pelo desfolhador.

Assim como foi encontrado neste trabalho, muitas outras plantas exibem correlação negativa entre a densidade de tricomas e as respostas alimentares, indicando uma barreira física a herbivoria (LEVIN, 1973; WEI et al., 2000). Estes limitam o acesso de insetos à superfície da planta, além do mais, alguns tipos de tricomas exalam compostos voláteis que repelem insetos que se alimentam das plantas, e um menor número médio deles pode reduzir esta capacidade de defesa das plantas, favorecendo o ataque de herbívoros (TOSCANO et al., 2001).

Paron e Lara (2005) trabalhando com feijoeiros, sugeriram que plantas mais pubescentes podem dificultar a alimentação dos crisomelídeos. Tal fato fica bem evidenciado na curva de tendência da regressão (Figura 2) mostrando que a densidade de tricomas foi inversamente proporcional à massa foliar consumida nas três cultivares de soja. Estes resultados obtidos concordam com os encontrados por HEYER et al. (1986) em feijoeiro e por Kanno (1996) em soja com outras espécies de crisomelídeos. 


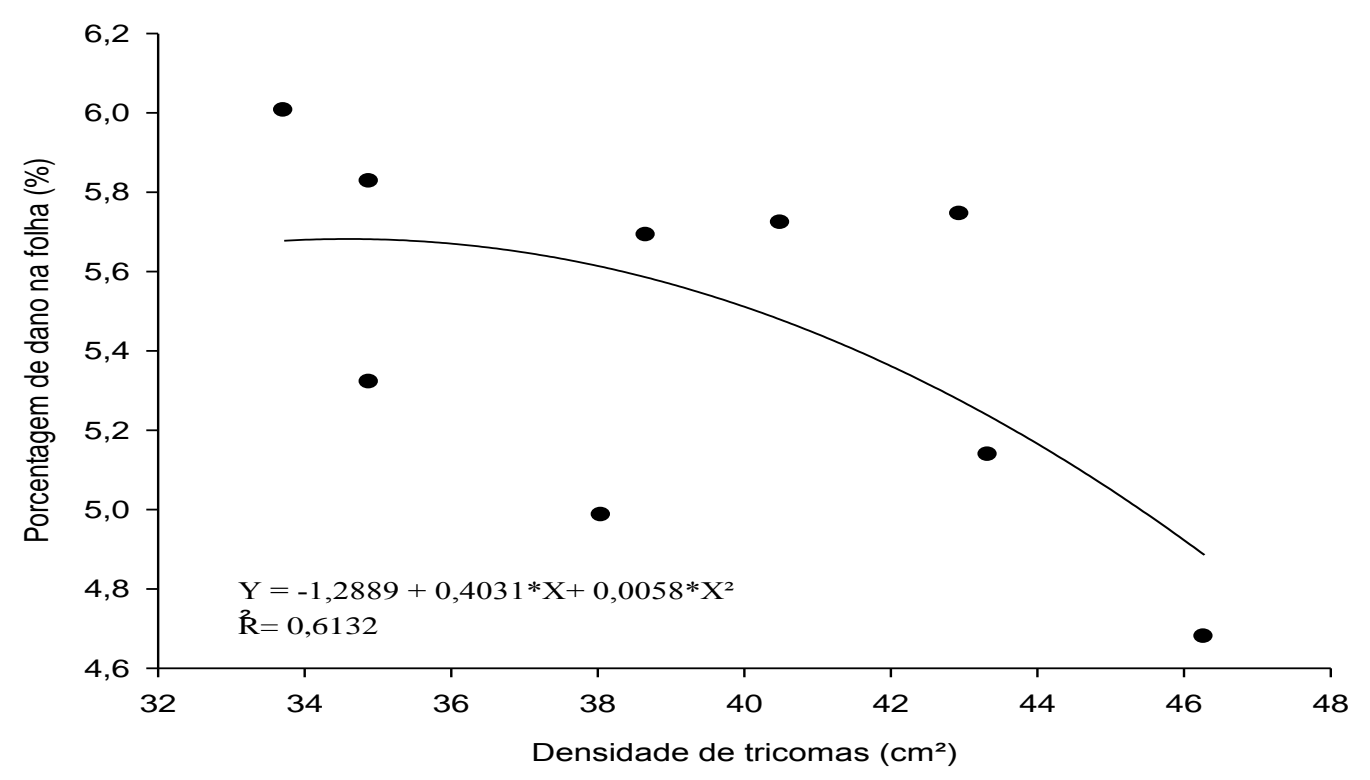

Figura 3. Densidades de tricomas, independentemente da cultivar, em função da quantidade de massa foliar consumida por Cerotoma arcuata.

Assim, o melhoramento de cultivares de soja visando a resistência ao ataque de pragas desfolhadoras é de fundamental importância, principalmente com relação a densidade de tricomas, pois uma cultivar altamente produtivo poder ter essa característica comprometida pelo severo ataque destes insetos. Além do mais a combate de pragas por resistência de plantas apresentas inúmeras vantagens ambientais sobre os outros métodos de combate, especialmente o controle químico, que justificam investimentos em pesquisas mais aprofundadas.

\section{CONCLUSÃO}

Os tricomas desempenham papel importante na proteção das plantas ao ataque da C. arcuata, de forma que o cultivar
M8766RR apresenta resistência do tipo nãopreferência para alimentação deste desfolhador.

\section{AGRADECIMENTOS}

Agradecemos ao CNPq e a CAPES pelas bolsas concedidas aos autores, e ainda ao professor Joenes Pelucci e os alunos de graduação pela colaboração.

\section{REFERÊNCIAS}

\section{ALMEIDA, J. C. Herbivoria e mecanismos} de defesa vegetal. In: NOGUEIRA, R. J. M. C; ARAúJO, E. L.; WILlADiNO L. G., CAVALCANTE U. M. T. (Org.). Estresses ambientais: danos e benefícios em plantas. Recife. p. 389-396. 2005. 
DIDONET, J.; FRAGOSO, D. B.; PELUZIO, J. M.; SANTOS, G.R. Flutuação populacional de pragas e seus inimigos naturais em soja no projeto rio formoso - Formoso do Araguaia TO, Brasil. Acta Amazônica, v. 28, n. 1, p. $67-74,1998$.

HAJEK, A. E. Natural Enemies: An Introduction to Biological Control. Cambridge University Press. 2004.

HEYER, W.; CRUZ, B.; CHIANG-LOK, M. L. Comportamiento y preferencia de los adultos de Diabrotica balteata, Andrector ruficornis, Systena basalis (Coleoptera: Chrysomelidae) y Empoasca fabae (Hemiptera: Cicadellidae), en frijol. Ciencias de La Agricultura, [S.1.], v. 27, p. 61-76, 1986.

KANNO, H. Role of leaf pubescence in soybean resistance to the false melon beetle, Atrachya menetriesi Faldermann (Coleoptera: Chrysomelidae). Applied Entomology and Zoology, Oxford, v. 31, n. 4, p. 597-603, 1996.

KARABOURNIOTIS, G.; BORNMAN, J. F.; LIAKOURA, V. Different leaf surface characteristics of threes grate cultivars affect leaf optical properties as measured white fibre optics: possible implication in stress tolerance. Australian Journal of Plant Physiology. v. 26, p. 47-53, 1999.

KOGAN, M. Criação de insetos: bases nutricionais e aplicação em programas de manejo de pragas. In: VI Congresso Brasileiro de Entomologia, Campinas, 1980. Anais...Campinas, p. 45-75, 1980.

LEVIN, D.A. The role of trichomes in plant defense. The Quarterly Review of Biology, New York, 48, v. 1, p. 3-5, 1973.

LIMA, A. C.S.; LARA, F. M. Resistência de Genótipos de Soja à Mosca Branca Bemisia tabaci (Genn.) Biótipo B (Hemiptera: Aleyrodidae). Neotropical Entomology. v. 33, p. 71-75, 2004.

MEDEIROS, J. D.; MORRETES, B. L. Dimensões da folha e herbivoria em Miconia cabucu Hoehne (Melastomataceae)".

Biotemas. v. 8, p. 97-112, 1995.

PARON, M. J. F. O.; LARA, F. M. Relação entre tricomas foliares de genótipos de feijoeiro comum, Phaseolus vulgaris L. e resistência a Diabrotica speciosa Germar, 1824 (Coleoptera: Chrysomelidae). Ciência agrotecnológica, Lavras, v. 29, n. 4, p. 894-898, 2005.

TOSCANO, L. C.; BOIÇA JÚNIOR, A. L.; SANTOS, J. M.; ALMEIDA, J. B. S. A.. Tipos de tricomas em genótipos de Lycopersicon. Horticultura Brasileira, Brasília, v. 19, n. 3, p. 204-206. 2001.

WEI, J.; ZOU, L.; RONGPING, K.; LIPING, H.. Influence of leaf tissue structure on host feeding selection by pea leafminer Liriomyza huidobrensis (Diptera: Agromyzidae)". Zoological Studies. v. 39, p.295-300, 2000. 